\title{
FITOSSOCIOLOGIA DA VEGETAÇÃO ARBÓREA DO PARQUE NACIONAL DO IGUAÇU
}

\author{
PHYTOSOCIOLOGY OF TREE VEGETATION IN IGUAÇU NATIONAL PARK
}

\author{
Ronan Felipe de Souza ${ }^{1}$ Sebastião do Amaral Machado ${ }^{2}$ Franklin Galvão ${ }^{3}$ Afonso Figueiredo Filho ${ }^{4}$
}

\begin{abstract}
RESUMO
Fitossociologia da Vegetação Arbórea do Parque Nacional do Iguaçu - O Parque Nacional do Iguaçu está inserido no Bioma Mata Atlântica, sendo considerado o maior Parque extra-amazônico brasileiro. Apesar de sua importância e expressiva área de superfície florestal, poucos são os estudos científicos relacionados à sua vegetação. Com o objetivo de atender esta demanda foi realizado inventário fitossociológico da vegetação arbórea por meio de parcelas instaladas em diferentes condições ambientais, buscando a máxima representatividade ambiental possível. Na classificação da vegetação por meio da TWINSPAN as florestas foram separadas inicialmente em ambientes montanos e submontanos. Uma região de transição entre as florestas estacionais e ombrófilas foi observada no ambiente montano, com altitude acima de 700 m. A Floresta Estacional Montana foi observada em altitudes entre 600 a $700 \mathrm{~m}$ e a Floresta Estacional Submontana, imediatamente abaixo, foi separada em duas subformações devido às variações fisionômicas regidas pela geomorfologia e variabilidade hídrica existente. A vegetação arbórea do Parque Nacional do Iguaçu é, de acordo com os resultados encontrados, um remanescente de grande relevância para a preservação das espécies florestais no sul do Brasil, entre as quais, se destacam Aspidosperma polyneuron Müll. Arg., Araucaria angustifolia (Bertol.) Kuntze, Euterpe edulis Mart. e Ilex paraguariensis A. St.-Hil. Palavras-chave: formações vegetais; classificação das parcelas; espécies indicadoras; espécies preferenciais.
\end{abstract}

\section{ABSTRACT}

Phytosociology of tree vegetation in Iguaçu National Park is inserted within Atlantic Forest biome and is considered the largest Brazilian non-Amazon Park. Despite its importance and its significant forest area, there are few scientific studies related to its vegetation. In order to meet this demand, we conducted a phytosociological inventory of the tree vegetation by means of plots installed in different environments, striving to achieve optimum environmental representation. In the classification of vegetation by TWINSPAN the forests were initially separated into ambient montane and submontane. An ecotone region between seasonal and araucaria forests was observed in the montane site, at an altitude above $700 \mathrm{~m}$. The semideciduous forest montane was observed at altitudes of 600-700 meters. The Forest Seasonal Submontane in the lowlands was separated into two subformations, Typical and Humid, due to physiognomic variations regulated by geomorphology and humidity. According to the results, the tree vegetation of Iguaçu National Park is a remnant of great importance for the conservation of forest species in southern Brazil, among which stand out Aspidosperma polyneuron Müll. Arg., Araucaria angustifolia (Bertol.) Kuntze, Euterpe edulis Mart.

1 Engenheiro Florestal, Dr. Professor Colaborador, Centro de Ciências Exatas e da Terra, Universidade Estadual do Oeste do Paraná, Rua Universitária, 1619, CEP 85819-110, Cascavel (PR), Brasil. ronanflorestal@gmail.com

2 Engenheiro Florestal, PhD., Professor Sênior do Programa de Pós-graduação em Engenharia Florestal, Centro de Ciências Agrárias, Universidade Federal do Paraná, Av. Pref. Lothário Meissner, 900, CEP 80210-170, Curitiba (PR), Brasil.samachado@ufpr.br

3 Engenheiro Florestal, Dr., Professor Sênior do Programa de Pós-graduação em Engenharia Florestal, Centro de Ciências Agrárias, Universidade Federal do Paraná, Av. Pref. Lothário Meissner, 900, CEP 80210-170, Curitiba (PR), Brasil. fgalvao@ufpr.br

4 Engenheiro Florestal, PhD., Professor Sênior do Programa de Pós-graduação em Engenharia Florestal, Centro de Ciências Agrárias, Universidade Federal do Paraná, Av. Pref. Lothário Meissner, 900, CEP 80210-170, Curitiba (PR), Brasil. afigfilho@gmail.com

Recebido para publicação em 7/07/2014 e aceito em 11/11/2015 
and Ilex paraguariensis A. St.-Hil.

Keywords: vegetation formations; classification of plots; indicative species; preference species.

\section{INTRODUÇÃO}

A expressiva variabilidade biológica somada à paisagem singular de rara beleza cênica das Cataratas do Iguaçu e a sua estrutura voltada para o turismo ecológico tornam o Parque Nacional do Iguaçu (PNI) um exemplo de integração entre a conservação e o uso sustentável dos recursos naturais. Atualmente, esta Unidade de Conservação (UC) encontra-se integralmente protegida e abriga o maior remanescente florestal do bioma Mata Atlântica no Sul do Brasil (FERREIRA, 1999).

Apesar da efetividade na fiscalização com objetivo de manter preservado este remanescente, anteriormente à criação do Parque, em 1939, muito da vegetação na porção sul e sudoeste onde ocorreu o estabelecimento de cultivos agrícolas e pastagens já havia sido degradada. Nas demais áreas do Parque, ao contrário, a exploração seletiva de madeira deixou remanescentes florestais fragmentados, causando o quase desaparecimento de algumas espécies mais procuradas em função das propriedades da madeira (FERREIRA, 1999).

Considerando este histórico, foram previstos para o Parque estudos detalhados da vegetação nas suas diferentes regiões (INSTITUTO BRASILEIRO DE DESENVOLVIMENTO FLORESTAL; FUNDAÇÃO BRASILEIRA PARA A CONSERVAÇÃO DA NATUREZA, 1981). Os quais, no entanto, se resumem ao levantamento florestal realizado por Péllico Netto et al. (1968) e a Avaliação Ecológica Rápida efetuada por Ziller (1998), para fins da revisão do Plano de Manejo (FERREIRA, 1999).

Na tentativa de obter informações precisas, estudos da vegetação tendem a adicionar à florística uma classificação dos ambientes por meio da análise multivariada que, por sua vez, tem apresentado resultados satisfatórios (ARAUJO et al., 2004; PAULA et al., 2004; WANG; KENT; FANG, 2007; SCIPIONI et al., 2011; MARCUZZO; ARAÚJO; LONGHI, 2013). Outra análise muito utilizada pelos ecólogos é denominada fitossociologia, na qual, se considera a estrutura horizontal e vertical da vegetação e são identificadas as espécies de maior importância da comunidade (MUELLER-DOMBOIS; ELLENBERG, 1974; VAN DEN BERG; OLIVEIRA-FILHO, 2000; SILVA et al., 2003; BARDDAL et al., 2004; ALMEIDA; AMARAL; SILVA, 2004; OLIVEIRA; AMARAL, 2005; MAINGI; MARSH, 2006; ARAUJO et. al., 2010). Neste tipo de análise, diversidade e equabilidade são informações adicionais, utilizadas pelos pesquisadores como índices de comparação, bem como, para atestar o estado de preservação da vegetação (MAGURRAN, 2011).

Neste trabalho, um inventário florestal com o uso de parcelas permanentes foi realizado considerando os seguintes objetivos: (I) Identificar as formações vegetais existentes por meio da classificação das parcelas considerando as espécies indicadoras e preferenciais; (II) Descrever e comparar a fitossociologia da vegetação arbórea nas diferentes formações vegetais existentes.

\section{MATERIAL E MÉTODOS}

\section{Área de estudo}

O PNI fica localizado no oeste do estado do Paraná $\left(25^{\circ} 27^{\prime} 38,89^{\prime \prime} \mathrm{S} ; 53^{\circ} 55^{\prime} 19.54^{\prime \prime} \mathrm{W}\right)$. Atualmente apresenta uma área total de 185.262,5 hectares e sua vegetação faz parte do bioma Mata Atlântica. Segundo o mapa da vegetação paranaense o Parque possui três tipologias vegetais: a Floresta Estacional Semidecidual (FES), nas suas formações Montana e Submontana; a Floresta Ombrófila Mista (FOM) Montana; e a Formação Pioneira com Influência Fluvial (FPIF) (ITCG, 2009). Ziller (1998) descreveu, no entanto, que a vegetação do Parque é composta pela FES, um ecótono entre a FES e a FOM e as FPIF.

A região geográfica que o PNI ocupa é caracterizada por um clima Cfa (ALVARES et al., 2013). Na porção norte a temperatura e o regime hídrico são registrados por uma estação meteorológica situada no município de Cascavel (245' $\mathrm{S}$ e $\left.53^{\circ} 33^{\prime} \mathrm{W}\right)$. Com $660 \mathrm{~m}$ de altitude, esta estação registrou entre os anos de 1973 e 1998 uma temperatura média anual de $19,6{ }^{\circ} \mathrm{C}$ e precipitação média anual de $1.971 \mathrm{~mm}$. Nesta região observa-se mínima absoluta de temperatura no mês mais frio de $4,2{ }^{\circ} \mathrm{C}$ negativos (INSTITUTO 
AGRONÔMICO DO PARANÁ, 2014). A porção sul do Parque, com temperaturas mais elevadas e menor recorrência de geadas, pode ser representada por uma estação meteorológica situada no município de São Miguel do Iguaçu $\left(25^{\circ} 26^{\prime}\right.$ S e $54^{\circ} 22^{\prime}$ W) com 260 m de altitude. Nesta região a temperatura média anual registrada no período de 1983 a 1997 foi igual a $21,4{ }^{\circ} \mathrm{C}$ e a precipitação média anual de $1.841 \mathrm{~mm}$ (INSTITUTO AGRONÔMICO DO PARANÁ, 2014).

O relevo do Parque é subordinado à bacia hidrográfica do rio Iguaçu e apresenta gradiente de altitude que varia de 100 a $750 \mathrm{~m}$ à medida que se afasta da calha deste rio. O relevo é caracterizado por colinas onduladas à forte onduladas, localmente escarpado com padrão de drenagem retangular e subretangular na porção norte e colinas suavemente onduladas a onduladas, com padrão de drenagem dendrítico, retangular a subretangular na porção sul (FERREIRA, 1999). O solo é, em sua maioria, de alta fertilidade, formado por derrames de lavas basálticas que abrangem a Bacia do Paraná (BIGARELLA; LEPREVOST; BOLSANELLO, 1985). Bhering (2007) publicou a mais recente classificação de solos realizada no Paraná, para a região do PNI foram identificadas as seguintes classes: CHERNOSSOLO RÊNDZICO Órtico; GLEISSOLO Háplico; NEOSSOLO Litólico Eutrófico; LATOSSOLO VERMELHO Disférrico; LATOSSOLO VERMELHO Eutroférrico e NITOSSOLO VERMELHO Eutroférrico. Dentre os quais, predominam os NITOSSOLOS e LATOSSOLOS.

\section{Dados e análises}

Foram instalados sete grupos de três parcelas ao longo do gradiente de altitude existente, desde a região às margens do rio Iguaçu até a região do extremo norte do Parque, instalados a cada 100 metros (m) de altitude e interiorizados na vegetação no sentido oeste-leste (Figura 1). Em cada altitude, as parcelas foram posicionadas com distância variável entre si e paralelas ao curso dos rios, distribuídas ao longo das rampas de drenagem desde sua base até as regiões de platô, próximas aos divisores de água. No total, foram instaladas 21 parcelas permanentes com superfície amostral de $2.000 \mathrm{~m}^{2}(20 \times 100 \mathrm{~m})$, totalizando 4,20 ha.

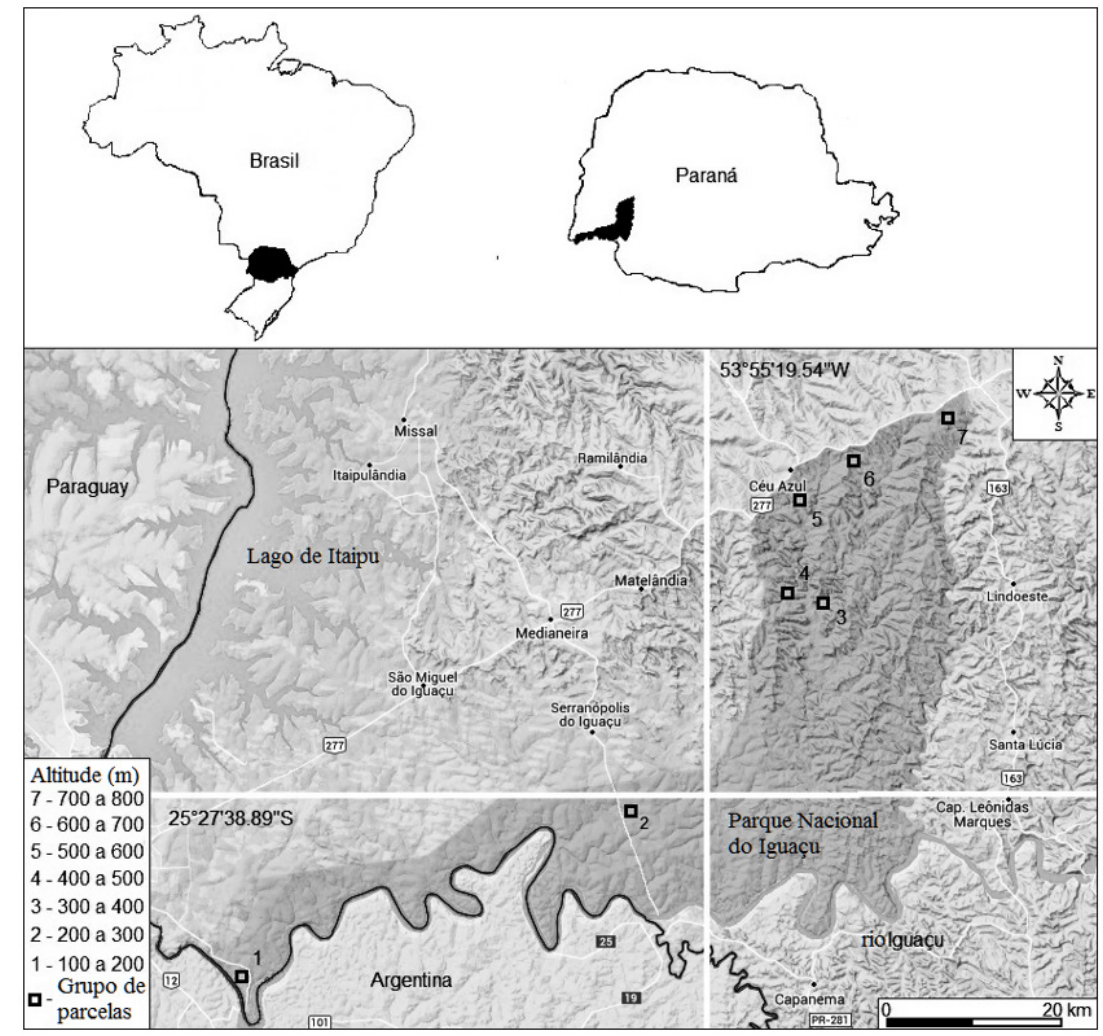

FIGURA 1: Área de estudo e grupos de parcelas instaladas no Parque Nacional do Iguaçu. FIGURE 1: Study area and groups of plots installed in Iguaçu National Park. 
Este delineamento foi adotado para garantir, ao máximo, a observação das variações ambientais existentes nos diferentes ambientes, considerando as diferentes combinações de altitude e posição na rampa de drenagem. O procedimento foi adaptado dos trabalhos de Oliveira-Filho et al. (1994); Ferreira-Junior et al. (2007); Higuchi et al. (2008) e Giehl e Jarenkow (2008).

Nas parcelas foram coletados o material botânico e as informações de diâmetro a 1,30 m acima do solo e altura do ponto de inversão morfológica de todos os indivíduos vivos (DAP $\geq 5,0 \mathrm{~cm}$ ). O ponto de inversão morfológica foi identificado pela bifurcação que descaracteriza o fuste da árvore. O material botânico foi identificado no Museu Botânico de Curitiba e enviado para especialistas, quando necessário. A classificação de famílias segue APG III (ANGIOSPERM PHYLOGENY GROUP, 2009) e a verificação da nomenclatura das espécies foi realizada por meio de pesquisa online no Missouri Botanical Garden (www.tropicos.org).

A classificação dos solos foi realizada em campo até o terceiro nível categórico seguindo os critérios estabelecidos em EMBRAPA (2006). Para isso, foi realizada coleta de perfil do solo no centro de cada parcela até um metro de profundidade com auxílio de trado holandês e, determinadas em laboratório as características químicas e físicas de uma amostra composta homogeneizada, formada por cinco amostras simples de solo superficial (zero - $20 \mathrm{~cm}$ de profundidade) coletadas ao longo da linha central da parcela.

A classificação das parcelas na vegetação foi realizada por meio Two Way Indicator Species Analysis (TWINSPAN) (HILL; BUNCE; SHAW, 1975) com auxílio do programa PC-ORD for Windows versão 6.0 (MCCUNE; MEFFORD, 2011). A análise baseou-se em uma matriz de densidades contendo as espécie que apresentaram dez ou mais árvores. Considerando a metodologia de amostragem e a base de dados, foram utilizados os seguintes parâmetros para a classificação: grupo mínimo de divisão igual a três; número máximo de espécies indicadoras até cinco; número máximo de espécies na tabela final igual a 200 e, por fim; dois níveis de divisão. Após análise da matriz de densidade foram identificados os níveis adequados de corte para as pseudoespécies em zero, quatro, oito, 12, 20 e 30. O Índice de Similaridade de Jaccard $(J$ ') (MULLER-DOMBOIS; ELLENBERG, 1974) foi calculado entre os grupos formados na TWINSPAN para atestar a efetividade da classificação.

A eficiência amostral foi verificada para cada grupo de parcelas formado na TWINSPAN, esta análise levou em consideração a variabilidade da amostra, o erro de amostragem admitido de $10 \%$ e a significância fixada em 5\% (PELLICO NETTO; BRENA, 1997). Os parâmetros utilizados foram a densidade (N) (árvores.ha $\left.{ }^{-1}\right)$ e a área basal $(\mathrm{G})\left(\mathrm{m}^{2} \cdot \mathrm{ha}^{-1}\right)$. A abrangência florística das parcelas na vegetação arbórea foi verificada por meio da curva espécie-área, onde pode ser observada a relação entre a riqueza de espécies e o esforço amostral acumulado (FELFILI et al., 2011).

O estudo da fitossociologia foi realizado com auxílio do Microsoft Office Excel versão 2007, no qual, foram calculados os valores absolutos e relativos para densidade, área basal e frequência de ocorrência de cada espécie nas parcelas. Por meio do somatório da densidade e área basal relativas foi obtido o valor de cobertura percentual de cada espécie (MULLER-DOMBOIS; ELLENBERG, 1974), este índice varia de 0 a $200 \%$. A estrutura vertical foi analisada pela frequência relativa das espécies nos estratos definidos da seguinte forma: emergente e dossel, imediatamente abaixo do dossel e no sub-bosque.

O cálculo da diversidade florística foi realizado por meio do Índice de Shannon $\left(H^{\prime}\right)$ e para a obtenção da Equabilidade ( $E^{\prime}$ ) adotou-se o procedimento proposto por Pielou (1975). Os índices utilizados encontram-se descritos em Magurran (2011).

\section{RESULTADOS E DISCUSSÃO}

\section{Classificação das parcelas na vegetação}

Inicialmente não foi possível obter uma classificação adequada das parcelas, pois, foi verificada forte influência da ocorrência descontinua e das densidades variáveis de Euterpe edulis ao longo das parcelas em baixas altitudes. Originalmente, esta espécie ocorria de forma abundante e continua nestas regiões do Sul do Brasil (MAACK, 1968; LEITE; KLEIN, 1990; IBGE, 2012). Ferreira (1999) justificou esta distribuição da espécie devido à sua intensa exploração e à dificuldade de fiscalização nas fronteiras do PNI, que ainda encontrava-se sob pressão antrópica na época. Desta forma, esta espécie foi excluída da 
matriz de densidades.

Após a exclusão de Euterpe edulis foi observada uma classificação das parcelas com significado ecológico, consideradas a florística e fisionomia observada em campo. A similaridade florística, medida pelo índice Jaccard $\left(J^{\prime}\right)$, atestou a eficiência das divisões realizadas, bem como, corroborou com a identificação da região de Ecótono na região Norte do Parque (Tabela 1).

Contrário a este resultado é a atribuição com significado ecológico apenas para divisões com autovalor superior a 0,3, proposta por Kent e Coker (1992). Fatores intrínsecos ao Parque como, por exemplo, a ocorrência de uma zona de transição entre duas tipologias vegetais e a homogeneidade dos solos podem ser a causa dos autovalores de divisão encontrados, uma vez que afetaram positivamente a similaridade florística entre os grupos de parcelas.

No primeiro nível de divisão foram selecionadas espécies indicadoras e grupos preferenciais para

TABELA 1: Classificação das parcelas na vegetação e suas respectivas características ambientais.

TABLE 1: Plot classifications in the vegetation and its environmental characteristics.

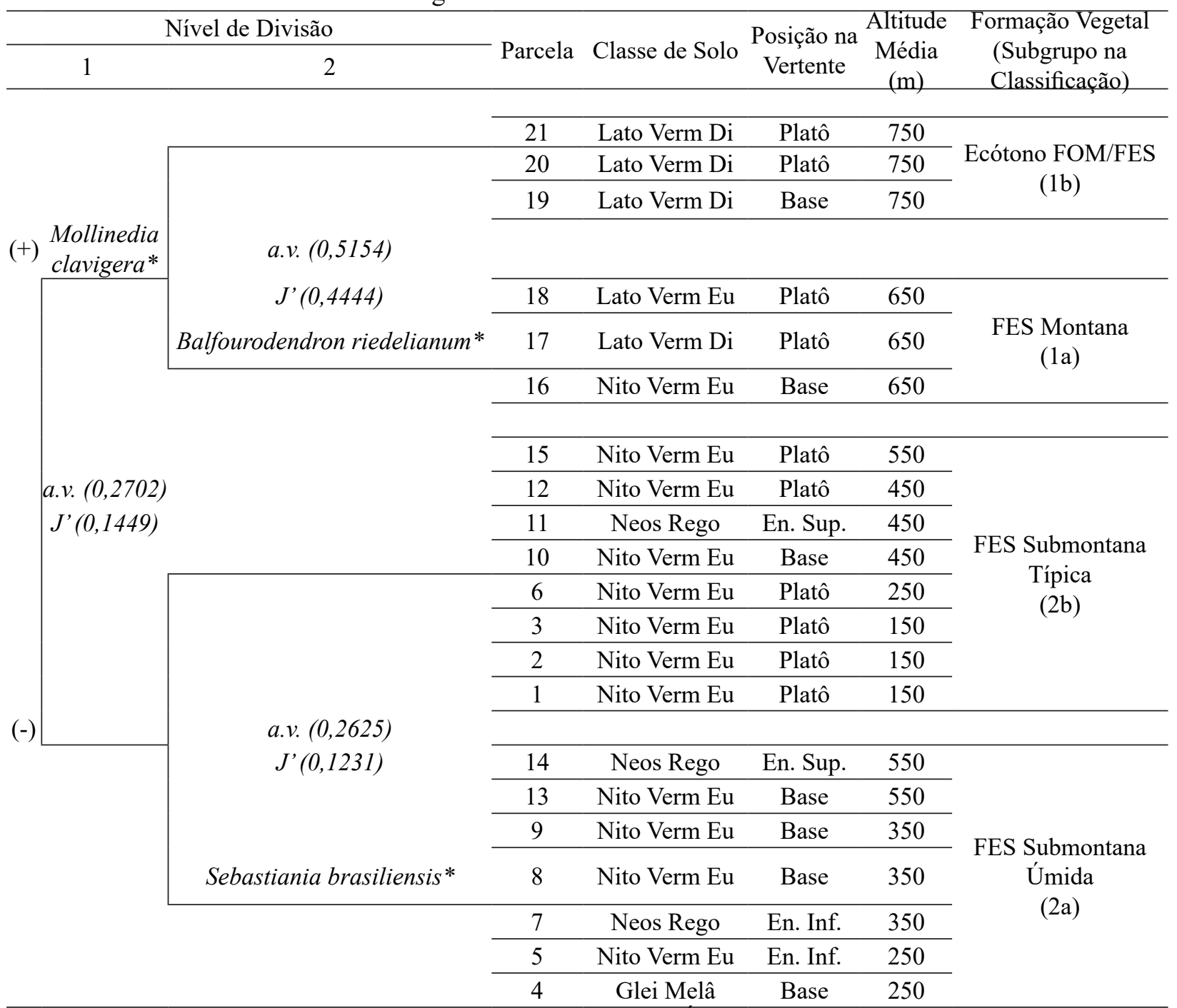

Em que: * Espécies indicadoras; a.v. - Autovalor de divisão; $J^{\prime}$ - Indice de similaridade de Jaccard; Nito Verm NITOSSOLO VERMELHO Eutrófico, Glei Melâ - GLEISSOLO MELÂNICO Tb Eutrófico, Neos Rego - NEOSSOLO REGOLITICO Eutrófico, Lato Verm Eu - LATOSSOLO VERMELHO Eutrófico, Lato Verm Di - LATOSSOLO VERMELHO Distrófico; Base - Base de vertente; En. Sup. - encosta superior de vertente; En. Inf. - encosta inferior de vertente; FOM - Floresta Ombrófila Mista; FES - Floresta Estacional Semidecidual. 
as diferentes condições ambientais de temperatura e de regime hídrico, regidas pelo gradiente altitudinal. Nesta divisão foi observada a separação das florestas montanas (+) e submontanas (-), nas maiores e menores altitudes respectivamente.

O grupo positivo teve como espécie indicadora Mollinedia clavigera, típica de florestas ombrófilas (SAUERESSIG, 2012). As espécies preferenciais foram Araucaria angustifolia, Alchornea glandulosa, Casearia obliqua, Casearia sylvestris, Cupania vernalis, Ficus luschnathiana, Ilex paraguariensis, Ixora venulosa, Jacaranda micrantha, Myrocarpus frondosus, Ocotea indecora, Ocotea silvestris, Psychotria carthagenensis, Sebastiania commersoniana, Senegalia recurva, Styrax acuminatus e Styrax leprosus.

O grupo negativo não apresentou espécie indicadora e se caracterizou por espécies típicas de FES, dentre elas, Acacia bimucronata, Bastardiopsis densiflora, Cordia americana, Pilocarpus pennatifolius e Urera baccifera. Outras espécies preferenciais foram Cecropia pachystachya, Eugenia subterminalis, Hennecartia omphalandra, Inga marginata e Lonchocarpus nitidus.

Silva e Soares-Silva (2000) e Bianchini et al. (2003) trabalharam em FES Submontana no norte do Paraná e identificaram a ocorrência de duas destas espécies preferenciais, entre elas Cordia americana e Bastardiopsis densiflora. Scipioni et al. (2011) identificaram também para FES Submontana Urera baccifera e Cordia americana. Outras duas espécies, Inga marginata e Holocalyx omphalandra, ocorreram no trabalho destes autores. No entanto, tais espécies, juntamente com Cecropia pachystachya, Eugenia subterminalis e Lonchocarpus nitidus são encontradas frequentemente em florestas ombrófilas (SAUERESSIG, 2012; GASPER et al., 2013a). Ríos, Galvão e Curcio (2010) identificaram a presença e alta importância de Pilocarpus pennatifolius em uma floresta montana, o que também a desqualifica como preferencial de florestas estacionais submontanas. Dentre as espécies preferenciais de FES Submontana consta ainda Acacia bimucronata, verificada ocorrendo exclusivamente em ambientes Submontanos por Carvalho (2004).

O grupo de espécies não preferenciais no primeiro nível de divisão foi composto por: Aspidosperma polyneuron, Alchornea triplinervia, Allophylus edulis, Annona emarginata, Balfourodendron riedelianum, Banara tomentosa, Cabralea canjerana, Calliandra foliolosa, Campomanesia xanthocarpa, Casearia decandra, Cedrela fissilis, Cordia ecalyculata, Cordia trichotoma, Chrysophyllum gonocarpum, Chrysophyllum marginatum, Citrus sinensis, Dalbergia frutescens, Diatenopteryx sorbifolia, Eugenia burkartiana, Guarea kunthiana, Holocalyx balansae, Jacaratia spinosa, Lonchocarpus campestris, Luehea divaricata, Machaerium stipitatum, Matayba elaeagnoides, Myrsine umbellata, Nectandra lanceolata, Nectandra megapotamica, Ocotea diospyrifolia, Parapiptadenia rigida, Plinia rivularis, Prockia crucis, Prunus myrtifolia, Sebastiania brasiliensis, Seguieria guaranitica, Syagrus romanzoffiana, Sorocea bonplandii, Trichilia catigua, Trichilia claussenii e Trichilia elegans.

No segundo nível de divisão, o grupo positivo sofreu uma nova divisão, os subgrupos foram denominados (1a) e (1b). A espécie indicadora na divisão foi B. riedelianum, observada no subgrupo (1a). Neste subgrupo as espécies preferenciais foram Aspidosperma polyneuron, Calliandra foliolosa, Cecropia pachystachya, Eugenia burkartiana, Ficus luschnathiana, Guarea kunthiana, Holocalyx balansae, Inga marginata, Inga venulosa, Jacaratia spinosa, Myrocarpus frondosus, Plinia rivularis, Psychotria carthagenensis, Sebastiania brasiliensis, Sebastiania commersoniana, Seguieria guaranitica, Trichilia catigua, Trichilia claussenii, Trichilia elegans e Urera baccifera.

O subgrupo (1b) apresentou as seguintes espécies preferenciais: Alchornea glandulosa, Allophylus edulis, Annona emarginata, Araucaria angustifolia, Banara tomentosa, Casearia decandra, Casearia obliqua, Citrus sinensis, Dalbergia frutescens, Hennecartia omphalandra, Ilex paraguariensis, Luehea divaricata, Matayba elaeagnoides, Myrsine umbellata, Nectandra lanceolata, Ocotea indecora, Parapiptadenia rigida, Senegalia recurva e Styrax acuminatus. O grupo de espécies não preferenciais nesta divisão foi composto por Alchornea triplinervia, Cabralea canjerana, Campomanesia xanthocarpa, Casearia sylvestris, Cedrella fissilis, Chrysophyllum gonocarpum, Chrysophyllum marginatum, Cordia ecalyculata, Cordia trichotoma, Cupania vernalis, Diatenopteryx sorbifolia, Jacaranda micrantha, Lonchocarpus campestris, Mollinedia clavigera, Machaerium stipitatum, Nectandra megapotamica, Ocotea silvestris, Ocotea diospyrifolia, Prockia crucis, Prunus myrtifolia, Styrax leprosus, Syagrus romanzoffiana e Sorocea bonplandii.

Pode ser observado na Tabela 2 que várias espécies típicas de florestas estacionais ocorreram 
no subgrupo (1b), alterando a fisionomia da vegetação, entre elas Aspidosperma polyneuron, Cordia trichotoma, Jacaratia spinosa e Myrocarpus frondosus, caracterizando uma florística de Ecótono entre FOM e FES nesta região. No subgrupo (1a), apenas Mollinedia clavigera ocorreu associada às espécies estacionais. Esta vegetação foi então denominada apenas como FES, com a atribuição Montana devido às condições ambientais presentes nas parcelas, bem como, pela diferenciação florística em relação às parcelas do grupo negativo, situadas em menores altitudes.

Na classificação realizada pelo IBGE (2012) com base em cotas altimétricas, a formação Montana da FES ocorre em altitudes entre 400 e $1.000 \mathrm{~m}$ para a região, podendo ser substituída pela FOM a partir de $500 \mathrm{~m}$. O resultado encontrado, estabelecendo um Ecótono FOM/FES em altitudes em torno de $750 \mathrm{~m}$, pode ser associado à maior interiorização do PNI no continente e o seu correspondente regime de chuvas menos frequente (OLIVEIRA-FILHO; FONTES, 2000), bem como, às características pedológicas que modificam gradativamente das parcelas entre 750 e $650 \mathrm{~m}$.

Péllico Netto et al. (1968) realizaram a caracterização da vegetação do PNI por meio de fotografias aéreas e identificaram a existência de florestas dominadas por Araucaria angustifolia nos vales dos maiores rios na região Norte, estendendo-se por altitudes próximas de $500 \mathrm{~m}$. Fato que pode ser justificado pelo sentido norte-sul dos vales e a consequente redução da incidência de raios solares, o que permite a manutenção de menores temperaturas por um maior período ao longo do dia e contribui para a manutenção da umidade no ambiente; característica que também foi descrita por Ferreira (1999). IBGE (2012) denomina este sistema de transição como "Tensão Ecológica", descrevendo o que Veloso et al. (1975) definiu como "mosaico de áreas edáficas", onde a vegetação encravada guarda sua identidade ecológica, sem se misturar, devido às características do solo e ambiente.

O grupo negativo, obtido na primeira divisão, sofreu também uma separação, os subgrupos formados foram denominados (2a) e (2b), tendo Sebastiania brasiliensis como espécie indicadora do subgrupo (2a). As parcelas deste subgrupo foram posicionadas nos vales que acompanham os cursos d'água, onde a variabilidade pedológica e maior umidade foram marcantes, no entanto, sem ocorrência de hidromorfismo ou deposição aluvial no solo devido ao leito dos cursos d'água estar controlado por falhas geológicas. Na região mais ao sul, a parcela quatro apresentou um GLEISSOLO MELÂNICO Tb Eutrófico e, devido à alta densidade de $S$. brasiliensis compôs também o subgrupo (2a). As espécies preferenciais deste subgrupo foram: Banara tomentosa, Casearia obliqua, Cordia americana, Cupania vernalis, Dalbergia frutescens, Eugenia subterminalis, Lonchocarpus nitidus, Matayba elaeagnoides, Myrocarpus frondosus, Sebastiania commersoniana, Seguieria guaranitica e Trichilia elegans. Este subgrupo foi denominado FES Submontana Úmida.

Destas espécies, apenas Cordia obliqua e Eugenia subterminalis não foram encontradas por Bianchini et al. (2003) em um estudo de FES Aluvial no norte do Paraná. Estas duas espécies, somadas a Myrocarpus frondosus e Seguieria guaranitica, também não foram encontradas por Scipioni, Galvão e Longhi (2013). As demais espécies foram recorrentes na Floresta Estacional Aluvial/Submontana no trabalho destes autores, corroborando com o resultado encontrado.

O subgrupo ( $2 \mathrm{~b}$ ) correspondeu às parcelas posicionadas nos platôs, com solos profundos e menor umidade. Duas parcelas foram exceção neste subgrupo, 10 e 11, posicionadas em uma rampa de drenagem subordinada a um vale orientado no sentido oeste-leste com menor umidade devido à maior incidência de luz. As espécies preferenciais deste subgrupo foram Acacia bimucronata, Aspidosperma polyneuron, Alchornea glandulosa, Casearia sylvestris, Cecropia pachystachya, Citrus sinensis, Cordia ecalyculata, Eugenia burkartiana, Ficus luschnathiana, Guarea kunthiana, Inga marginata, Ocotea indecora, Ocotea silvestris e Trichilia claussenii. Este subgrupo foi denominado FES Submontana Típica.

Deste grupo de espécies foram identificadas em comum com o trabalho de Silva e Soares-Silva (2000), para uma FES Submontana do norte do Paraná Aspidosperma polyneuron, Alchornea glandulosa, Guarea kunthiana e Inga marginata. Outra espécie recorrente foi Trichilia claussenii, a qual aparece com grande relevância nos trabalhos de Jarenkow e Waechter (2001), Scipioni et al. (2011) e Scipioni, Galvão e Longhi (2013). Estes últimos autores identificaram também Sorocea bonplandii e Cordia ecalyculata na formação submontana da floresta estacional.

As espécies não preferências que ocorreram entre os subgrupos (2a) e (2b) foram Alchornea triplinervia, Annona emarginata, Allophylus edulis, Bastardiopsis densiflora, Balfourodendron riedelianum, 
TABELA 2: Espécies com mais dez árvores e respectivas frequência percentual de ocorrência nas parcelas (FR), densidade absoluta (DE) e valor de cobertura nas formações vegetais do Parque Nacional do Iguaçu.

TABLE 2: Species with ten or more trees and the frequency of occurrence percentage in the plots (FR), absolute density (DE) and cover value in the vegetation formations of National Iguaçu Park.

\begin{tabular}{|c|c|c|c|c|c|c|}
\hline \multirow[b]{2}{*}{ Espécie } & \multirow[b]{2}{*}{ FR } & \multirow[b]{2}{*}{$\mathrm{DE}$} & \multicolumn{4}{|c|}{ Valor de Cobertura (\%) } \\
\hline & & & Ecótono FOM/FES & FES Montana & $\begin{array}{c}\text { FES } \\
\text { Submontana } \\
\text { Típica }\end{array}$ & $\begin{array}{c}\text { FES } \\
\text { Submontana } \\
\text { Úmida }\end{array}$ \\
\hline Acacia bimucronata DC. & 23,81 & 10 & - & - & 1,04 & - \\
\hline Alchornea glandulosa Poepp. & 23,81 & 18 & 2,70 & 0,15 & 0,69 & - \\
\hline Alchornea triplinervia (Spreng.) Müll. Arg. & 80,95 & 68 & 6,32 & 14,75 & 3,94 & 0,54 \\
\hline Allophylus edulis (A. St.-Hil., et al.) Hieron. Ex Niederl. & 61,9 & 59 & 5,41 & 0,53 & 1,25 & 2,34 \\
\hline Annona emarginata (Schltdl.) H. Rainer & 47,62 & 21 & 1,02 & - & 1,19 & 0,59 \\
\hline Araucaria angustifolia (Bertol.) Kuntze & 9,52 & 12 & 9,17 & - & - & - \\
\hline Aspidosperma polyneuron Müll. Arg. & 47,62 & 34 & 0,16 & 16,46 & 13,30 & 0,09 \\
\hline Balfourodendron riedelianum (Engl.) Engl. & 80,95 & 122 & - & 10,72 & 7,70 & 8,89 \\
\hline Banara tomentosa $\mathrm{Clos}$ & 38,1 & 13 & 1,32 & 0,17 & 0,22 & 0,65 \\
\hline Bastardiopsis densiflora (Hook. \& Arn.) Hassl. & 38,1 & 21 & - & - & 0,86 & 4,66 \\
\hline Cabralea canjerana (Vell.) Mart. & 85,71 & 134 & 16,27 & 8,79 & 10,07 & 1,19 \\
\hline Calliandra foliolosa Benth. & 23,81 & 24 & - & 0,16 & 0,51 & 1,48 \\
\hline Campomanesia xanthocarpa Mart. Ex O. Berg. & 90,48 & 68 & 5,28 & 0,34 & 4,07 & 1,35 \\
\hline Casearia decandra Jacq. & 47,62 & 35 & 3,62 & - & 0,72 & 1,30 \\
\hline Casearia obliqua Spreng. & 28,57 & 17 & 2,94 & - & 0,07 & 0,30 \\
\hline Casearia silvestris $\mathrm{Sw}$. & 42,86 & 26 & 2,55 & 0,63 & 0,60 & 0,48 \\
\hline Cecropia pachystachya Trécul & 42,86 & 19 & - & 0,83 & 1,53 & 0,22 \\
\hline Cedrella fissilis Vell. & 80,95 & 65 & 7,46 & 2,73 & 4,09 & 3,39 \\
\hline Chrysophyllum gonocarpum (Mart. \& Eichler ex Miq.) Engl. & 95,24 & 104 & 1,21 & 0,91 & 6,45 & 4,98 \\
\hline Chrysophyllum marginatum (Hook. \& Arn.) Radlk. & 90,48 & 64 & 1,77 & 2,13 & 1,82 & 2,43 \\
\hline Citrus sinensis (L.) Osbek * & 23,81 & 21 & 0,16 & - & 1,49 & 0,09 \\
\hline Cordia americana (L.) Gottschling \& J. S. Mill. & 42,86 & 28 & - & - & 3,69 & 17,67 \\
\hline Cordia ecalyculata Vell. & 66,67 & 26 & 0,35 & 0,68 & 1,50 & 0,27 \\
\hline Cordia trichotoma (Vell.) Arráb. Ex Steud. & 52,38 & 22 & 0,48 & 0,15 & 2,27 & 0,92 \\
\hline Cupania vernalis Cambess. & 42,86 & 24 & 1,28 & 2,05 & - & 1,44 \\
\hline Dalbergia frutescens (Vell.) Britton & 47,62 & 25 & 1,00 & - & 0,26 & 1,44 \\
\hline Diatenopteryx sorbifolia Radlk. & 80,95 & 56 & 1,41 & 0,60 & 4,16 & 4,48 \\
\hline Eugenia burkartiana (D. Legrand) D. Legrand & 33,33 & 10 & - & 0,31 & 0,50 & 0,09 \\
\hline Eugenia subterminalis DC. & 19,05 & 18 & - & - & 0,22 & 1,58 \\
\hline Euterpe edulis Mart. & 61,90 & 735 & - & 40,92 & 40,23 & 0,28 \\
\hline Ficus luschnathiana (Miq.) Miq. & 28,57 & 10 & - & 1,38 & 1,65 & - \\
\hline Guarea kunthiana A. Juss. & 33,33 & 67 & - & 1,44 & 4,56 & - \\
\hline Hennecartia omphalandra J. Poiss. & 42,86 & 22 & 0,17 & - & 0,83 & 1,71 \\
\hline Holocalyx balansae Micheli & 66,67 & 36 & - & 4,95 & 3,27 & 2,12 \\
\hline Ilex paraguariensis A. St.-Hil. & 14,29 & 40 & 9,87 & - & - & - \\
\hline Inga marginata Willd. & 42,86 & 22 & - & 0,57 & 1,06 & 0,47 \\
\hline Ixora velutina Wall. & 28,57 & 51 & - & 6,47 & 0,22 & 0,75 \\
\hline Jacaranda micrantha Cham. & 42,86 & 12 & 0,78 & 1,18 & 0,40 & 0,54 \\
\hline Jacaratia spinosa (Aubl.) A. DC. & 57,14 & 17 & 0,35 & 4,10 & 1,08 & 0,83 \\
\hline Lonchocarpus campestris Mart. Ex Benth. & 52,38 & 40 & 3,38 & 0,46 & 0,70 & 2,62 \\
\hline Lonchocarpus nitidus (Vogel) Benth. & 28,57 & 12 & - & - & 0,14 & 1,91 \\
\hline Luehea divaricata Mart. & 38,10 & 31 & 6,21 & - & 1,22 & 5,95 \\
\hline Machaerium stipitatum (DC.) Vogel & 85,71 & 143 & 4,55 & 3,74 & 7,46 & 12,83 \\
\hline Matayba elaeagnoides Radlk. & 23,81 & 15 & 4,60 & - & 0,07 & 0,34 \\
\hline Mollinedia clavigera Tul. & 28,57 & 45 & 5,73 & 1,59 & - & - \\
\hline Myrocarpus frondosus Allemão & 38,10 & 25 & 0,50 & 3,55 & 0,33 & 1,31 \\
\hline
\end{tabular}


TABELA 2: Continuação...

TABLE 2: Continued...

\begin{tabular}{|c|c|c|c|c|c|c|}
\hline \multirow[b]{2}{*}{ Espécie } & \multirow[b]{2}{*}{ FR } & \multirow[b]{2}{*}{$\mathrm{DE}$} & \multicolumn{4}{|c|}{ Valor de Cobertura $(\%)$} \\
\hline & & & Ecótono FOM/FES & FES Montana & $\begin{array}{c}\text { FES } \\
\text { Submontana } \\
\text { Típica }\end{array}$ & $\begin{array}{c}\text { FES } \\
\text { Submontana } \\
\text { Úmida }\end{array}$ \\
\hline Myrsine umbellata Mart. & 80,95 & 57 & 3,96 & - & 0,77 & 2,77 \\
\hline Nectandra lanceolata Nees \& Mart. & 71,43 & 60 & 15,47 & 0,15 & 3,20 & 3,87 \\
\hline Nectandra megapotamica (Spreng.) Mez. & 95,24 & 137 & 0,54 & 4,28 & 9,43 & 14,31 \\
\hline Ocotea diospyrifolia (Meisn.) Mez. & 100,00 & 134 & 5,69 & 3,26 & 6,28 & 13,86 \\
\hline Ocotea indecora (Schott) Mez. & 23,81 & 10 & 1,40 & - & 0,48 & - \\
\hline Ocotea silvestris Vattimo-Gil & 61,90 & 73 & 2,58 & 11,20 & 0,89 & 0,93 \\
\hline Parapiptadenia rigida (Benth.) Brenan & 66,67 & 56 & 11,30 & 1,31 & 3,93 & 4,18 \\
\hline Pilocarpus pennatifolius Lem. & 33,33 & 19 & - & - & 0,55 & 1,15 \\
\hline Plinia rivularis (Cambess.) Rotman & 42,86 & 50 & - & 4,37 & 0,48 & 3,89 \\
\hline Prockia crucis P. Browne ex L. & 28,57 & 14 & 0,68 & 0,32 & 0,72 & 0,26 \\
\hline Prunus myrtifolia (L.) Urb. & 66,67 & 37 & 10,10 & 1,81 & 0,37 & 1,27 \\
\hline Psychotria carthagenensis Jacq. & 28,57 & 25 & 0,16 & 0,88 & 0,20 & 1,46 \\
\hline Sebastiania brasiliensis Spreng. & 76,19 & 134 & 0,59 & 1,23 & 1,01 & 11,71 \\
\hline Sebastiania commersoniana (Baill.) L. B. Sm. \& Downs & 28,57 & 12 & 0,17 & 1,26 & - & 0,45 \\
\hline Seguieria guaranitica Speg. & 52,38 & 23 & - & 0,37 & 0,78 & 1,77 \\
\hline Senegalia recurva (Benth.) Seigler \& Ebinger & 19,05 & 13 & 0,65 & - & 0,51 & 0,39 \\
\hline Sorocea bonplandii (Baill.) W.C. Burger, et al. & 85,71 & 241 & 5,28 & 15,12 & 6,45 & 1,50 \\
\hline Styrax acuminatus Pohl & 9,52 & 25 & 6,29 & - & - & - \\
\hline Styrax leprosus Hook. \& Arn. & 28,57 & 23 & 4,72 & 0,56 & - & 0,79 \\
\hline Syagrus romanzoffiana (Cham.) Glassman & 90,48 & 92 & 6,90 & 0,72 & 1,79 & 7,24 \\
\hline Trichilia catigua A. Juss. & 76,19 & 80 & 0,16 & 2,24 & 2,54 & 2,89 \\
\hline Trichilia claussenii C. DC. & 33,33 & 42 & - & 4,13 & 1,58 & 0,56 \\
\hline Trichilia elegans A. Juss. & 47,62 & 31 & - & 0,44 & 0,13 & 2,57 \\
\hline Urera baccifera (L.) Gaudich. & 57,14 & 67 & - & 0,17 & 1,32 & 4,98 \\
\hline
\end{tabular}

Em que: FOM = Floresta Ombrófila Mista; FES = Floresta Estacional Semidecidual; * Espécie exótica.

Cabralea canjerana, Caseariadecandra, Cedrella fissilis, Calliandrafoliolosa, Chrysophyllum gonocarpum, Chrysophyllum marginatum, Campomanesia xanthocarpa, Cordia trichotoma, Diatenopteryx sorbifolia, Holocalyx balansae, Hennecartia omphalandra, Ixora venulosa, Jacaranda micrantha, Jacaratia spinosa, Lonchocarpus campestris, Luehea divaricata, Machaerium stipitatum, Myrsine umbellata, Nectandra lanceolata, Nectandra megapotamica, Ocotea diospyrifolia, Pilocarpus pennatifolius, Plinia rivularis, Prockia crucis, Prunus myrtifolia, Parapiptadenia rigida, Sorocea bonplandii, Syagrus romanzoffiana, Trichilia catigua e Urera baccifera.

Muchailh et al. (2010), comentando seus resultados, indicaram o uso de espécies não ripárias para recuperação de áreas de encosta em uma bacia hidrográfica na região de entorno do PNI. O agrupamento florístico destas áreas de fragilidade ambiental com os ambientes de recarga iônica, na base dos vales patamarizados do PNI, é contrário à recomendação sugerida pelos autores, salvo aqueles locais onde as vertentes são de pequena extensão e no sentido oeste-leste, resultando em uma menor umidade no ambiente. Sugere-se para estas regiões a utilização do grupo de espécies preferenciais descritas na subformação Úmida da FES Submontana, bem como as espécies que apresentaram maior cobertura fitossociológica, garantindo o sucesso da recuperação florestal.

\section{Eficiência amostral e abrangência florística}

Ao adotar uma superfície amostral de $2.000 \mathrm{~m}^{2}$ esperava-se diminuir a variabilidade em densidade 
e a área basal entre as parcelas. Esta superfície amostral, bem superior àquela comumente utilizada em levantamentos fitossociológicos (BUDKE; JARENKOW; OLIVEIRA-FILHO, 2007; FERREIRAJÚNIOR, et al., 2007; HIGUCHI et al., 2008; SCIPIONI et al., 2012), contribuiu também para uma maior consistência dos resultados, já que diminui erros de extrapolação para estas duas variáveis fitossociológicas (AUGUSTYNCZIK et al., 2013).

O delineamento experimental, a alta diversidade de espécies e suas respectivas variações de densidade e área basal dentro das formações vegetais, no entanto, fizeram com que um maior número de parcelas fosse necessário para atingir a precisão requerida. Assim, cabe ressaltar que as generalizações sobre a importância das espécies nas formações devem ser aceitas com cautela.

O número de parcelas necessárias para estimar a densidade com a precisão requerida seria de 177 , 18, 68 e 29, respectivamente para o Ecótono FOM/FES, FES Montana, FES Submontana Típica e FES Submontana Úmida. Da mesma forma, para a estimativa da área basal seriam necessárias 126, 46, 44 e 26 parcelas, respectivamente para cada formação vegetal. Para o total da vegetação do PNI seriam necessárias 35 e 26 parcelas, respectivamente para a densidade e área basal.

$\mathrm{Na}$ análise da abrangência florística, com 10 parcelas foi possível amostrar 151 espécies, ou seja, $90 \%$ do total. As 11 parcelas restantes contribuíram pouco para o aumento do número de espécies, somando apenas 16 e indicando que, entre estas parcelas, um grande número de espécies ocorreu em comum. Com 20 parcelas, $100 \%$ das espécies já haviam sido amostradas (Figura 2).

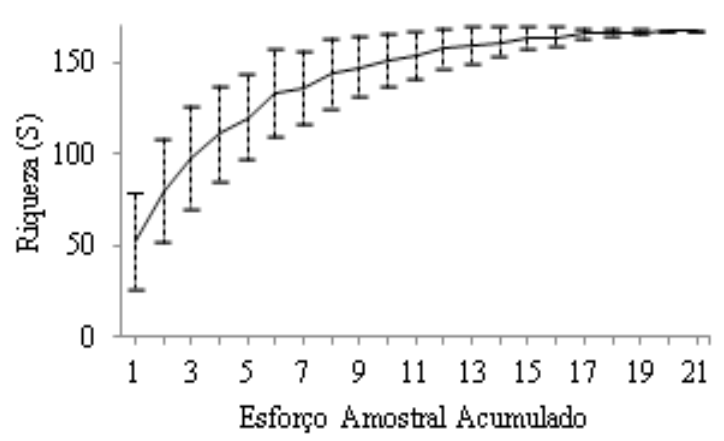

FIGURA 2: Relação entre a riqueza de espécies $(S)( \pm 1$ desvio padrão) e o esforço amostral acumulado. FIGURE 2: Ratio between the species richness $(\mathrm{S})( \pm 1 \mathrm{SD})$ and the cumulative sampling effort.

\section{Fitossociologia}

Gasper et al. (2013b) destacaram que nas florestas ombrófilas do estado de Santa Catarina a riqueza de espécies é maior que nas florestas estacionais. No PNI, a região do Ecótono FOM/FES apresentou a menor riqueza de espécies, resultado que foi justificado pelo maior número de parcelas instaladas nas florestas estacionais.

Mesmo com a pressão antrópica recorrente, Euterpe edulis foi a espécie de maior expressão, apresentando valores de cobertura expressivos em duas das quatro formações. Corroborando esse resultado, Jarenkow e Waechter (2001) identificaram a espécie entre as espécies com maior importância em florestas de baixa altitude, mesmo considerando a forte pressão antrópica a qual estava submetida.

$\mathrm{Na}$ região do Ecótono FOM/FES, com exceção de Cabralea canjerana, espécie com maior plasticidade ambiental (RÍOS; GALVÃO; CURCIO, 2010), as espécies apresentaram valores próximos para área basal e densidade, expressa também pela maior equabilidade $\left(E^{\prime}\right)$, característica desse tipo de ambiente (IBGE, 2012). Fisionomicamente esta região diferenciou-se da FES Montana e Submontana pela predominância de espécies ombrófilas, entre elas, Araucaria angustifolia no dossel e Ilex paraguariensis no sub-bosque (Tabela 3).

Dentre as espécies de maior importância, a única Lauraceae observada com elevado valor de cobertura neste ambiente foi Nectandra lanceolata, diferentemente dos demais ambientes, em menores altitudes, onde Nectandra megapotamica foi a mais representativa. Ao observar os trabalhos de Jarenkow e 
TABELA 3: Fitossociologia das dez espécies de maior valor de cobertura para as formações vegetais identificadas no Parque Nacional do Iguaçu.

TABLE 3: Phytosociology of the ten species with the highest cover value for the vegetation formations identified in Iguaçu National Park.

\begin{tabular}{|c|c|c|c|c|c|c|c|c|c|c|c|}
\hline \multirow{2}{*}{ Formação Vegetal } & \multirow{2}{*}{$S^{\prime}$} & \multirow{2}{*}{$H^{\prime}$} & \multirow{2}{*}{$E^{\prime}$} & \multirow{2}{*}{ Espécie } & \multirow{2}{*}{$\begin{array}{l}\mathrm{VC} \\
(\%) \\
\end{array}$} & \multirow{2}{*}{$\begin{array}{c}\mathrm{G} \\
\left(\mathrm{m}^{2} \cdot \mathrm{ha}^{-1}\right)\end{array}$} & \multirow{2}{*}{$\begin{array}{c}\mathrm{N} \\
\left(\text { árv. } \text { ha }^{-1}\right)\end{array}$} & \multirow{2}{*}{$\begin{array}{l}\text { FR } \\
(\%)\end{array}$} & \multicolumn{3}{|c|}{ FR Estrato Vertical (\%) } \\
\hline & & & & & & & & & 1 & 2 & 3 \\
\hline \multirow{12}{*}{$\begin{array}{l}\text { Ecótono } \\
\text { FOM/FES }\end{array}$} & \multirow{12}{*}{78} & \multirow{12}{*}{3,74} & \multirow{12}{*}{0,86} & Cabralea canjerana & 16,27 & 97 & 2,27 & 100 & 16,67 & 25,00 & 58,33 \\
\hline & & & & Nectandra lanceolata & 15,47 & 47 & 3,27 & 100 & 55,17 & 24,14 & 20,69 \\
\hline & & & & Parapiptadenia rigida & 11,30 & 32 & 2,45 & 100 & 35,00 & 40,00 & 25,00 \\
\hline & & & & Prunus myrtifolia & 10,10 & 37 & 1,99 & 100 & 30,43 & 39,13 & 30,43 \\
\hline & & & & Ilex paraguariensis & 9,87 & 67 & 1,18 & 100 & 6,52 & 50,00 & 43,48 \\
\hline & & & & Araucaria angustifolia & 9,17 & 20 & 2,13 & 67 & 75,00 & 25,00 & - \\
\hline & & & & Cedrella fissilis & 7,46 & 28 & 1,43 & 100 & 30,00 & 45,00 & 25,00 \\
\hline & & & & Syagrus romanzoffiana & 6,90 & 37 & 1,07 & 100 & 13,64 & 59,09 & 27,27 \\
\hline & & & & Alchornea triplinervia & 6,32 & 32 & 1,03 & 100 & 13,04 & 52,17 & 34,78 \\
\hline & & & & Styrax acuminatus & 6,29 & 42 & 0,77 & 100 & 20,00 & 28,00 & 52,00 \\
\hline & & & & Outras espécies & 100,85 & 724 & 10,97 & - & - & - & - \\
\hline & & & & Total para o grupo & 200,00 & 1163 & 28,56 & - & - & - & - \\
\hline \multirow{12}{*}{$\begin{array}{l}\text { FES } \\
\text { Montana }\end{array}$} & \multirow{12}{*}{71} & \multirow{12}{*}{3,00} & \multirow{12}{*}{0,70} & Euterpe edulis & 40,92 & 370 & 4,04 & 100 & 2,25 & 55,86 & 41,89 \\
\hline & & & & Aspidosperma polyneuron & 16,46 & 22 & 5,69 & 100 & 46,15 & 38,46 & 15,38 \\
\hline & & & & Sorocea bonplandii & 15,12 & 165 & 0,59 & 100 & - & 1,01 & 98,99 \\
\hline & & & & Alchornea triplinervia & 14,75 & 32 & 4,71 & 100 & 20,83 & 37,50 & 41,67 \\
\hline & & & & Ocotea silvestris & 11,20 & 65 & 2,27 & 100 & 7,69 & 66,67 & 25,64 \\
\hline & & & & Balfourodendron riedelianum & 10,72 & 37 & 2,98 & 100 & 54,55 & 4,55 & 40,91 \\
\hline & & & & Cabralea canjerana & 8,79 & 22 & 2,72 & 100 & 20,00 & 33,33 & 46,67 \\
\hline & & & & Ixora venulosa & 6,47 & 67 & 0,38 & 100 & - & 5,00 & 95,00 \\
\hline & & & & Holocalyx balansae & 4,95 & 18 & 1,33 & 100 & 18,18 & 45,45 & 36,36 \\
\hline & & & & Plinia rivularis & 4,37 & 27 & 0,84 & 100 & - & 50,00 & 50,00 \\
\hline & & & & Outras espécies & 66,26 & 388 & 13,22 & - & - & - & - \\
\hline & & & & Total para o grupo & 200,00 & 1213 & 38,77 & - & - & - & - \\
\hline \multirow{12}{*}{$\begin{array}{l}\text { FES } \\
\text { Submontana } \\
\text { Típica }\end{array}$} & \multirow{12}{*}{110} & \multirow{12}{*}{3,35} & \multirow{12}{*}{0,71} & Euterpe edulis & 40,23 & 319 & 3,01 & 100 & 2,75 & 39,02 & 58,24 \\
\hline & & & & Aspidosperma polyneuron & 13,30 & 12 & 4,21 & 63 & 31,58 & 5,26 & 63,16 \\
\hline & & & & Cabralea canjerana & 10,07 & 33 & 2,36 & 100 & 26,42 & 39,62 & 33,96 \\
\hline & & & & Nectandra megapotamica & 9,43 & 28 & 2,30 & 100 & 28,89 & 44,44 & 26,67 \\
\hline & & & & Balfourodendron riedelianum & 7,70 & 31 & 1,62 & 88 & 42,86 & 10,20 & 46,94 \\
\hline & & & & Machaerium stipitatum & 7,46 & 29 & 1,60 & 88 & 25,53 & 34,04 & 40,43 \\
\hline & & & & Sorocea bonplandii & 6,45 & 59 & 0,22 & 100 & - & 2,11 & 97,89 \\
\hline & & & & Chrysophyllum gonocarpum & 6,45 & 33 & 1,12 & 100 & 13,46 & 51,92 & 34,62 \\
\hline & & & & Ocotea diospyrifolia & 6,28 & 25 & 1,32 & 100 & 17,07 & 39,02 & 43,90 \\
\hline & & & & Guarea kunthiana & 4,56 & 36 & 0,34 & 63 & - & 16,39 & 83,61 \\
\hline & & & & Outras espécies & 88,08 & 405 & 16,59 & - & - & - & - \\
\hline & & & & Total para o grupo & 200,00 & 1010 & 34,69 & - & - & - & - \\
\hline
\end{tabular}

Continua.. 
TABELA 3: Continuação...

TABLE 3: Continued...

\begin{tabular}{|c|c|c|c|c|c|c|c|c|c|c|c|}
\hline \multirow{2}{*}{ Formação Vegetal } & \multirow{2}{*}{$S^{\prime}$} & \multirow{2}{*}{$H^{\prime}$} & \multirow{2}{*}{$E^{\prime}$} & \multirow{2}{*}{ Espécie } & \multirow{2}{*}{$\begin{array}{l}\mathrm{VC} \\
(\%)\end{array}$} & \multirow{2}{*}{$\begin{array}{c}\mathrm{G} \\
\left(\mathrm{m}^{2} \cdot \mathrm{ha}^{-1}\right)\end{array}$} & \multirow{2}{*}{$\begin{array}{c}\mathrm{N} \\
\left(\text { árv. ha- }{ }^{-1}\right)\end{array}$} & \multirow{2}{*}{$\begin{array}{l}\text { FR } \\
(\%)\end{array}$} & \multicolumn{3}{|c|}{ FR Estrato Vertical (\%) } \\
\hline & & & & & & & & & 1 & 2 & 3 \\
\hline \multirow{12}{*}{$\begin{array}{l}\text { FES } \\
\text { Submontana } \\
\text { Úmida }\end{array}$} & \multirow{12}{*}{116} & \multirow{12}{*}{4,00} & \multirow{12}{*}{0,84} & Cordia americana & 17,67 & 17 & 4,92 & 86 & 54,29 & 25,71 & 20,00 \\
\hline & & & & Nectandra megapotamica & 14,31 & 54 & 2,58 & 100 & 19,74 & 35,53 & 44,74 \\
\hline & & & & Ocotea diospyrifolia & 13,86 & 44 & 2,79 & 100 & 23,81 & 42,86 & 33,33 \\
\hline & & & & Machaerium stipitatum & 12,83 & 49 & 2,29 & 100 & 22,86 & 24,29 & 52,86 \\
\hline & & & & Sebastiania brasiliensis & 11,71 & 79 & 0,90 & 100 & 0,87 & 15,65 & 83,48 \\
\hline & & & & Balfourodendron riedelianum & 8,89 & 36 & 1,51 & 100 & 25,49 & 37,25 & 37,25 \\
\hline & & & & Syagrus romanzoffiana & 7,24 & 36 & 0,99 & 100 & 17,65 & 62,75 & 19,61 \\
\hline & & & & Luehea divaricata & 5,95 & 8 & 1,59 & 43 & 50 & 8,33 & 41,67 \\
\hline & & & & Chrysophyllum gonocarpum & 4,98 & 32 & 0,44 & 100 & 2,22 & 37,78 & 60,00 \\
\hline & & & & Urera baccifera & 4,98 & 36 & 0,31 & 86 & - & - & 100,00 \\
\hline & & & & Outras espécies & 97,58 & 507 & 12,92 & - & - & - & - \\
\hline & & & & Total para o grupo & 200,00 & 898 & 31,24 & - & - & - & - \\
\hline
\end{tabular}

Em que: FOM = Floresta Ombrófila Mista; FES = Floresta Estacional Semidecidual; $S^{\prime}$ = Riqueza de espécies; $H^{\prime}$ = Índice de Shannon (nats); $E^{\prime}=$ Equabilidade; $\mathrm{VC}(\%)=$ Valor de cobertura; $\mathrm{G}\left(\mathrm{m}^{2} . \mathrm{ha}^{-1}\right)$ = Área basal por hectare; $\mathrm{N}\left(\right.$ árv.ha $\left.^{-1}\right)=$ Densidade por hectare; FR $(\%)=$ Frequência de ocorrência nas parcelas; FR Estrato Vertical $(\%)$ = Frequência percentual de ocorrência por estrato vertical: (1) Emergente e dossel; (2) Imediatamente abaixo do dossel; (3) Sub-bosque.

Waechter (2001), Holz, Placci e Quintana (2009), Ríos, Galvão e Curcio (2010) e Scipioni et al. (2011), este resultado também foi constatado e representa forte indicativo de preferência destas espécies em ambientes de maior e menor altitude, respectivamente.

A FES Montana apresentou fisionomia muito semelhante à FES Submontana Típica, com diversidade florística e equabilidade próximas e, no entanto, inferiores em relação ao Ecótono FOM/FES e a FES Submontana Úmida. Resultado atribuído à elevada densidade das espécies Euterpe edulis e Sorocea bonplandii, ambas consideradas clímax tolerantes à sombra.

A menor riqueza de espécies na FES Montana em comparação às FES Submontanas foi associada a menor superfície amostral, já que, a riqueza de espécies tende a aumentar em regiões de maior disponibilidade hídrica. Entre as 10 espécies de maior importância neste ambiente estão Alchornea triplinervia, Ocotea silvestris, Ixora venulosa, Holocalyx balansae e Plinia rivularis, as quais substituíram Nectandra megapotamica, Machaerium stipitatum, Chrysophyllum gonocarpum, Ocotea diospyrifolia e Guarea kunthiana, de maior importância na FES Submontana Típica, o que pode estar associado à redução na temperatura média anual e na fertilidade do solo.

Destaca-se ainda que as espécies de maior importância na FES Montana foram observadas também na FES Submontana, como foi o caso de Alchornea triplinervia, identificada também com o maior valor de importância nos trabalhos de Goetzke (1990) e Costa Filho, Nanni e Campos (2006). Dentre as demais espécies, Holocalyx balansae, Ocotea silvestris e Plinia rivularis foram encontradas com valores de importância intermediários na FES Submontana Típica do próprio PNI. Ixora venulosa apresentou baixa densidade nas menores altitudes, com exceção da parcela quatro, resultado provavelmente associado ao GLEISSOLO MELÂNICO Tb Eutrófico, exclusivo desta parcela.

Costa Filho, Nanni e Campos (2006) e Quiqui et al. (2007) identificaram também a presença de algumas das espécies da FES Submontana Típica no PNI com valores intermediários de importância para FES Submontana no noroeste do estado do Paraná, ocorrendo em associação a outras espécies da região central do Brasil. Estes autores destacaram apenas Chrysophyllum gonocarpum com valor de importância entre as dez melhor colocadas, corroborando com o levantamento no PNI. Quiqui et al. (2007) identificaram também Aspidosperma polyneuron, que ocorreu com alto valor de cobertura na FES Montana e Submontana Típica do PNI, entre as dez mais importantes. 
Holz, Placci e Quintana (2009) trabalharam com FES Submontana no nordeste da Argentina, às margens do Parque Nacional del Iguazú, em fragmentos onde a extração madeireira no passado foi seletiva, da mesma forma que a maioria das florestas analisadas no presente estudo. Em seus resultados, os autores identificaram para a região de Andresito cinco espécies em comum com as de maior importância para FES Submontana Típica do PNI. Foram elas: Chrysophyllum gonocarpum, Euterpe edulis, Guarea kunthiana, Nectandra. megapotamica e Cabralea canjerana. Outras espécies identificadas pelos autores ocorreram com menor valor de cobertura no PNI, entre elas: Alchornea glandulosa, Bastardiopsis densiflora e Diatenopteryx sorbifolia.

As FES Montana e Submontana Típica apresentaram fisionomia diferente daquela observada na FES Submontana Úmida, com árvores exuberantes no estrato emergente, logo acima do dossel relativamente aberto. Tais características são descritas por Maack (1968) e Leite e Klein (1990) para caracterizar as florestas estacionais de forma geral. Entre as espécies que apareceram caracterizando o dossel emergente estão, além de Aspidosperma polyneuron e Holocalyx balansae que tiveram altos valores de cobertura, Apuleia leiocarpa (Vogel) J.F. Macbr., Peltophorum dubium (Spreng.) Taub., Anadenanthera colubrina (Vell.) Brenan e Enterolobium contortisiliquum (Vell.) Morong que, devido ao baixo número de árvores amostradas, não foram incluídas na matriz de densidade.

Em área basal e densidade, as FES Montana e FES Submontana Típica apresentaram valores semelhantes entre si e ao trabalho de Scipioni et al. (2011). Destaca-se que estes autores identificaram uma fisionomia diferente daquela observada no PNI, uma vez que Euterpe edulis e Aspidosperma polyneuron não ocorreram, sendo substituídas no sub-bosque por Gymnanthes concolor (Spreng.) Müll. Arg. e dossel representado por um maior número de árvores de Holocalyx balansae, Apuleia leiocarpa e Diatenopteryx sorbifolia. Jarenkow e Waechter (2001) identificaram 1.885 árvores.ha $^{-1}$ em uma FES Submontana, bem acima dos resultados encontrados no PNI, justificado pela associação de elevadas densidades de Euterpe edulis, Gymnanthes concolor e Sorocea bonplandii.

No ambiente de FES Submontana Úmida, Cordia americana apresentou o maior valor de cobertura, seguida com valores muito próximos por Nectandra megapotamica, Ocotea diospyrifolia, Machaerium stipitatum e Sebastiania brasiliensis. Ao contrário dos ambientes aluviais do Sul do Brasil comumente dominados por Sebastiania commersoniana, este setor apresentou alta equabilidade e diversidade, com espécies de diferentes grupos ecológicos entre as de maior importância. Resultado justificado pela variabilidade geomorfológica e pedológica, bem como, pela predominância de solos sem hidromorfismo. Souza et al. (2003) retrataram em seu trabalho realizado em FES ripárias de relevo acidentado no estado de Minas Gerais as mesmas características. Os autores atribuíram isso à elevada equabilidade $\left(E^{\prime}=0,86\right) \mathrm{e}$ diversidade $\left(H^{\prime}=4,26\right.$ nats.árvore $\left.{ }^{-1}\right)$ encontradas à alta heterogeneidade ambiental na área do estudo.

Esta subformação também apresentou semelhança com a Floresta Estacional Aluvial/Submontana analisada por Scipioni, Galvão e Longhi (2013), na qual, os índices de diversidade $\left(H^{\prime}=3,42\right.$ nats.árvore $\left.{ }^{-1}\right)$ e equabilidade $\left(E^{\prime}=0,83\right)$ foram maiores que os observados na FES Submontana daquela área de estudo. Entre as 10 espécies de maior importância destacaram-se em comum Luehea divaricata e Sebastiania brasiliensis. Nectandra megapotamica e Cordia americana ficaram na décima terceira e décima sexta posições, respectivamente para um total de 83 espécies no trabalho destes autores. Outras espécies em comum foram Syagrus romanzoffiana e Chrysophyllum gonocarpum, no entanto, com menor importância.

De forma geral, as espécies melhor colocadas em valor de importância nos diferentes ambientes apresentaram frequência de ocorrência acima de 50\%. Luehea divaricata foi a única espécie que apresentou baixa dispersão no respectivo grupo (43\%), resultado da preferência característica da espécie por florestas com elevada umidade, bem como, solos mal drenados (BOTREL et al., 2002; ARAUJO et al., 2004; ZILLER, 1998).

A ocorrência de uma espécie nos diferentes estratos verticais da floresta reflete o seu sucesso de adaptação e assegura sua manutenção no ambiente. Em sua maioria, as espécies mais importantes em termos de valor de cobertura apresentaram ocorrência nos diferentes estratos verticais da floresta, com exceção de Sorocea bonplandii, Guarea kunthiana, Plinia rivularis e Ixora velutina, espécies adaptadas ao ambiente de sombra, seja imediatamente abaixo do dossel ou sub-bosque. Urera baccifera é um arbusto fanerofítico, o que justifica sua ocorrência exclusiva no estrato inferior da vegetação.

Araucaria angustifolia foi a única espécie, dentre as de maior importância, que não ocorreu nos 
estratos inferiores da vegetação, resultado que pode estar associado à região de Ecótono entre a FOM e FES, onde o clima mais seco e quente, comparativamente às regiões centrais do Sul do Brasil, dificulta sua regeneração na vegetação com dossel formado. Péllico Netto (1968) e Ziller (1998) destacaram a presença com altas densidades desta espécie nas florestas da região Centro-Norte do Parque, recobrindo os vales dos maiores rios onde a umidade é maior, fato que corrobora este resultado. A intensa exploração madeireira no Parque antes de sua criação em 1939 não pode ser descartada também como fator da condição atual desta espécie no local.

\section{CONCLUSÕES}

O Parque Nacional do Iguaçu apresenta uma elevada diversidade arbórea, composta na região Central e Sul pela FES Submontana e mais ao Norte, pelas FES Montana e um Ecótono entre a FOM e FES. Espécies típicas de florestas ombrófilas do Sul do Brasil predominaram fisionomicamente a vegetação nas altitudes superiores a $700 \mathrm{~m}$, favorecidas pela redução nas temperaturas, maior pluviosidade e solos de menor fertilidade.

A FES Montana apresentou menor riqueza de espécies em comparação à FES Submontana. Em termos fitossociológicos, a floresta Montana se assemelhou com a FES Submontana Típica, onde a maior estabilidade do solo e o regime hídrico estável favorecem o estabelecimento e crescimento de indivíduos de grande porte como Aspidosperma polyneuron que, por sua vez, tornam ambiente propício ao estabelecimento de populações com altas densidades de espécies clímax tolerantes a sombra, entre elas, Euterpe edulis e Sorocea bonplandii.

A FES Submontana Úmida, por outro lado, é caracterizada pela variabilidade pedológica e elevada umidade, que imprimem maior fragilidade ao ambiente e aceleram os processos dinâmicos da vegetação arbórea, afetando o estabelecimento de populações com altas densidades de uma única espécie.

\section{AGRADECIMENTOS}

Ao Instituto Chico Mendes de Conservação da Biodiversidade (ICMBio) pela autorização e disponibilização da estrutura física para realização deste trabalho. A Coordenação de Aperfeiçoamento de Pessoal de Nível Superior (CAPES) pelo apoio financeiro na forma de bolsa de estudos. Ao Conselho Nacional de Desenvolvimento Cientifico e Tecnológico (CNPQ) pela disponibilização recursos financeiros para execução dos trabalhos de campo.

\section{REFERÊNCIAS}

ALMEIDA, S. S.; AMARAL, D. D.; SILVA, A. S. L. Análise Florística e Estrutura de Florestas de Várzea no Estuário Amazônico. Acta Amazônica, Manaus, v. 34, n. 4, p. 513-524, 2004.

ALVARES, A. A. et al. Köppen's Climate Classification Map for Brazil. Meteorologische Zeitschrift, Stuttgart, v. 22, n. 6, p. 711-728, 2013.

ANGIOSPERM PHYLOGENY GROUP III. An update of the Angiosperm Phylogeny Group classification for the orders and families of flowering plants: APG III. Botanical Journal of the Linnean Society, Londres, v. 161, p. 105-121, 2009.

ARAUJO, M. M. et al. Análise de Agrupamento da Vegetação de um Fragmento de Floresta Estacional Decidual Aluvial, Cachoeira do Sul, RS, Brasil. Ciência Florestal, Santa Maria, v. 14, n. 1, p. 133-147, 2004.

ARAUJO, M. M. et al. Análise de Agrupamento em Remanescente de Floresta Ombrófila Mista. Ciência Florestal, Santa Maria, v. 20, n. 1, p. 1-18, 2010.

AUGUSTYNCZIK, A. L. D. et al. Avaliação do Tamanho de Parcelas e de intensidade de Amostragem em Inventários Florestais. Scientia Forestalis, Piracicaba, v. 41, n. 99, p. 361-368, 2013.

BARDDAL, M. L. et al. Fitossociologia do Sub-bosque de uma Floresta Ombrófila Mista Aluvial, no Município de Araucária, PR. Ciência Florestal, Santa Maria, v. 14, n. 1, p. 35-45, 2004.

BHERING, S. B. Mapa de solos do Estado do Paraná: escala 1:250.000. Rio de Janeiro: Embrapa 
Solos, 2007.

BIANCHINI, E. et al. Diversidade e Estrutura de Espécies Arbóreas em Área Alagável do Município de Londrina, Sul do Brasil. Acta Botânica Brasilica, Belo horizonte, v. 17, n. 3, p. 405-419, 2003.

BIGARELLA, J. J.; LEPREVOST, A.; BOLSANELLO, A. Rochas do Brasil. Rio de Janeiro: LTC; ADEA. $1985.310 \mathrm{p}$.

BOTREL, R. T. et al. Influência do Solo e Topografia sobre as Variações da Composição Florística e Estrutura da Comunidade Arbórea-arbustiva de uma Floresta Estacional Semidecidual em Ingaí, MG. Brazilian Journal of Botany, São Paulo, v. 25, p. 195-213, 2002.

BUDKE, J. C.; JARENKOW, J. A.; OLIVEIRA-FILHO, A. T. Relationships Between Tree Component Structure, Topography and Soils of a Riverside Forest, Rio Botucaraí, Southern Brazil. Plant Ecology, Netherlands, v. 189, p. 187-200, 2007.

CARVALHO, P. E. R. Maricá - Mimosa bimucronata. Colombo: EMBRAPA, 2004. 10 p. (Circular Técnica, 94).

COSTA FILHO, L. V.; NANNI, M. R.; CAMPOS, J. B. Floristic and Phytosociological Description of a Riparian Forest and the Relationship with the Edaphic Enviroment in Caiuá Ecological Station, Paraná, Brazil. Brazilian Archives of Biology and Technology, Curitiba, v. 49, n. 5, p. 785-798, 2006.

EMBRAPA. Sistema Brasileiro de Classificação de Solos. 2. ed. Brasília: Embrapa Produção de Informação; Rio de Janeiro: Embrapa Solos, 2006. 306 p.

FELFILI, J. M. et al. Fitossociologia no Brasil: métodos e estudos de casos. Viçosa: UFV, 2011. v. 1, 556 p. FERREIRA, L. M. Revisão do Plano de Manejo do Parque Nacional do Iguaçu - Encarte 5, com Vistas à Revisão do Plano de Manejo. Brasília: MMA, 1999. 353 p.

FERREIRA-JUNIOR, W. G. et al. Influence of Soils and Topographic Gradients on Tree Species Distribution in a Brazilian Atlantic Tropical Semideciduous Forest. Edinburgh Journal of Botany, Cambridge, v. 64, n. 2, p. 137-157, 2007.

GASPER, A. L. et al. Inventário Florístico Florestal de Santa Catarina: Espécies da Floresta Ombrófila Mista. Rodriguésia, Rio de Janeiro, v. 64, n. 2, p. 201-210, $2013 \mathrm{a}$.

GASPER, A. L. et al. Inventário Florístico Florestal de Santa Catarina: Espécies da Floresta Estacional Decidual. Rodriguésia, Rio de Janeiro, v. 64, n. 3, p. 427-443, 2013 b.

GIEHL, E. L. H.; JARENKOW, J. A. Gradiente Estrutural no Componente Arbóreo e Relação com Inundações em uma Floresta Ribeirinha, Rio Uruguai, Sul do Brasil. Acta Botânica Brasilica, Belo Horizonte, v. 22, n. 3, p. 741-753, 2008.

GOETZKE, S. Estudo Fitossociológico de uma Sucessão Secundária no Noroeste do Paraná, Proposta para Recuperação de Áreas Degradadas. 1990. 239 f. Dissertação (Mestrado em Botânica) - Universidade Federal do Paraná, Curitiba, 1990.

HIGUCHI, P. et al. Dinâmica da Comunidade Arbórea em um Fragmento de Floresta Estacional Semidecidual Montana em lavras, Minas Gerais, em Diferentes Classes de Solos. Árvore, Viçosa, MG, v. 32, n. 3, p. 417-426, 2008.

HILL, M. O.; BUNCE, R. G. H.; SHAW, M. W. Indicator Species Analysis, a Divisive Polythetic Method of Classification and its Application to a Survey of Native Pinewoods in Scotland. Journal of Ecology, Oxford, v. 63, n. 2, p. 597-613, 1975.

HOLZ, S.; PLACCI, G. P.; QUINTANA, R. D. Effects of History of use on secondary Forest regeneration in the Upper Parana Atlantic Forest (Misiones, Argentina). Forest Ecology and Management, Netherlands, v. 258, p. 1629-1642, 2009.

INSTITUTO AGRONÔMICO DO PARANÁ. Cartas Climáticas - Médias Históricas. [2014]. Disponível em: <http:/www.iapar.br/modules/conteudo /conteudo.php?conteudo=1070>. Acesso em: 24 abr. 2014.

INSTITUTO BRASILEIRO DE DESENVOLVIMENTO FLORESTAL; FUNDAÇÃO BRASILEIRA PARA A CONSERVAÇÃO DA NATUREZA. Plano de Manejo: Parque Nacional do Iguaçu. Brasília: MMA, 1981. $103 \mathrm{p}$.

IBGE. Manual Técnico da Vegetação Brasileira. 2. ed. Rio de Janeiro: EMBRAPA, 2012. 271 p. (Manuais Técnicos em Geociências).

INSTITUTO DE TERRAS, CARTOGRAFIA E GEOCIÊNCIAS. Formações fitogeográficas - Estado do Paraná. Curitiba: ITCG, 2009. 
JARENKOW, J. A.; WAECHTER, J. L. Composição, Estrutura e Relações Florísticas do componente Arbóreo de uma Floresta Estacional no Rio Grande do Sul, Brasil. Brazilian Journal of Botany, São Paulo, v. 24, n. 3, p. 263-272, 2001.

KENT, M.; COKER, P. Vegetation description analyses. London: Behaven Press, 1992. 363 p.

LEITE, P. F.; KLEIN, R. M. Vegetação. In: Geografia do Brasil: Região Sul. Rio de Janeiro: IBGE, 1990. v. 2, p. 113-150.

MAACK, R. Geografia Física do Estado do Paraná. Curitiba: Max Roesner, 1968. 350 p.

MAGURRAN, A. E. Medindo a Diversidade Biológica. Curitiba: UFPR, 2011. 261 p.

MAINGI, J. K.; MARSH, S. E. Composition, Structure, and Regeneration Patterns in a Gallery Forest Along the Tana River Near Bura, Kenya. Forest Ecology and Management, Netherlands, v. 236, p. 211-228, 2006.

MARCUZZO, S. B.; ARAÚJO, M. M.; LONGHI, S. J. Estrutura e Relações Ambientais de Grupos Florísticos em Fragmento de Floresta Estacional Subtropical. Árvore, Viçosa, MG, v. 37, n. 2, p. 275-287, 2013.

MCCUNE, B.; MEFFORD, M. J. PC-ORD. Multivariate Analysis of Ecological Data. Version 6.0. Oregon: MjM Software, 2011.

MUCHAILH, M. C. et al. Metodologia de planejamento de paisagens fragmentadas visando a formação de corredores ecológicos. Floresta, Curitiba, v. 40, n. 1, p. 147-162, 2010.

MUELLER-DOMBOIS, D.; ELLENBERG, H. Aims and methods of vegetation ecology. New York: J. Wiley, 1974. 547 p.

OLIVEIRA-FILHO, A. T. et al. Effect of Soils and Topography on the Distribution of Tree Species in a Tropical Riverine Forest in Southeastern Brazil. Journal of Tropical Ecology, Cambridge, v. 10, p. 233-258, 1994.

OLIVEIRA-FILHO, A. T.; FONTES, M. A. Patterns of Floristic Differentiation among Atlantic Forest in Southeastern Brazil and the Influence of Climate. Biotropica, Zurich, v. 32, n. 4b, p. 793-810, 2000.

OLIVEIRA, A. N.; AMARAL, I. L. Aspectos Florísticos, Fitossociológicos e Ecológicos de um Subbosque de Terra Firme na Amazônia Central, Amazonas, Brasil. Acta Amazônica, Manaus, v. 35, n. 1, p. 1-16, 2005.

PAULA, A. et al. Sucessão Ecológica da Vegetação Arbórea em uma Floresta Estacional Semidecidual, Viçosa, MG, Brasil. Acta Botânica Brasilica, Belo Horizonte, v. 18, n. 3, p. 407-423, 2004.

PÉLLICO NETTO, S. et al. Inventário de reconhecimento do Parque Nacional do Iguaçu. Curitiba: Centro de Pesquisas Florestais da Universidade Federal do Paraná; Instituto Brasileiro de Desenvolvimento Florestal, 1968. 29 p.

PÉLLICO NETTO, S.; BRENA, D. A. Inventário florestal. Curitiba: Editorado pelos autores, 1997. 316 p. PIELOU, E. C. Ecological Diversity. New York: Wiley InterScience. 1975. 165 p.

QUIQUI, E. M. D. et al. Estudo fitossociológico de um trecho da Floresta Estacional Semidecidual em Diamante do Norte, Estado do Paraná, Brasil. Acta Scientia Agronômica, Maringá, v. 29, n. 2, p. 283-290, 2007.

RÍOS, R. C.; GALVÃO, F.; CURCIO, G. R.; Estructura de las Principales Especies Arbóreas en el Parque Cruce Caballero y su Similitud Floristica con Areas de Argentina y de Brasil. Ciência Florestal, Santa Maria, v. 20, n. 2, p. 193-206, 2010.

SAUERESSIG, D. Levantamento dendrológico na Floresta Ombrófila Mista e Implementação de um sistema de identificação "Online". 2012. 117 f. Dissertação (Mestrado em Ciências Florestais) Universidade Federal do Paraná, Curitiba, 2012.

SCIPIONI, M. C. et al. Fitossociologia em Fragmento Florestal no Noroeste do Estado do Rio Grande do Sul. Ciência Florestal, Santa Maria, v. 21, n. 3, p. 407-417, 2011.

SCIPIONI, M. C. et al. Análise Fitossociológica de um Fragmento de Floresta Estacional em uma Catena de Solos no Morro do Cerrito, Santa Maria, RS. Ciência Florestal, Santa Maria, v. 22, n. 3, p. 457-466, 2012. SCIPIONI, M. C.; GALVÃO, F.; LONGHI, S. J. Composição florística e estratégias de dispersão e regeneração de grupos florísticos em florestas estacionais deciduais no Rio Grande do Sul. Floresta, Curitiba, v. 43 , n. 2 , p. $241-254,2013$.

SILVA, F. C.; SOARES-SILVA, L. H. Arboreal flora of the Godoy Forest State Park, Londrina, PR. Brazil. 
Edinburgh Journal of Botany, Cambridge, v. 57, n. 1, p. 107-120, 2000.

SILVA, V. F. et al. Caracterização Estrutural de um Fragmento de Floresta Semidecídua no Município de Ibituruna, MG. Cerne, Lavras, v. 9, n. 1, p. 92-106, 2003.

SOUZA, J. S. et al. Análise das variações florísticas e estruturais da comunidade arbórea de um fragmento de floresta semidecídua às margens do Rio Capivari, Lavras - MG. Árvore, Viçosa, MG, v. 27, n. 2, p. 185-206, 2003.

VAN DEN BERG, E.; OLIVEIRA-FILHO, A. T. Composição Florística e Estrutura Fitossociológica de uma Floresta Ripária em Itutinga, MG, e Comparação com Outras Áreas. Brazilian Journal of Botany, São Paulo, v. 23, n.3, 2000.

VELOSO, H. P. et al. As Regiões Fitoecológicas, sua Natureza e seus recursos econômicos: estudo fitogeográfico. In: FOLHA NA. 20, Boa Vista e parte das folhas NA.21 Tumucumaque, NB.20 Roraima e NB.21. Rio de Janeiro: Projeto Radam Brasil, 1975. p. 307-403. (Levantamento de recursos naturais, v. 8) WANG, X.; KENT, M.; FANG, X. Evergreen Broad-leaved Forest in Eastern China: its ecology and conservation and the importance of resprouting in forest restoration. Forest Ecology and Management, Netherlands, v. 245, p. 76-87, 2007.

ZILLER, S. R. Avaliação ecológica rápida do Parque Nacional do Iguaçu. 1. ed. Curitiba: IBAMA/ FUPEF Curitiba, 1998. 